\title{
Relationship between body image, anxiety, food-specific inhibitory control, and emotional eating in young women with abdominal obesity: a comparative cross- sectional study
}

\author{
Zhong-Hua He ${ }^{*}$ (D), Ming-De Li, Chan-Jun Liu and Xiao-Yue Ma
}

\begin{abstract}
Background: Abdominal fat deposition is a key component of obesity, which is associated with an increased risk for a number of mental disorders. The current study aims to explore the relationship between body image, anxiety, food-specific inhibitory control, and emotional eating in young women with abdominal obesity.

Method: A total of 224 participants were recruited: 168 were non-abdominal obesity and 56 were abdominal obesity. Participants completed the following questionnaires and behavioral tests: the Body Mass Index (BMI) -based Silhouette-Matching Test (SMT), the State-Trait Anxiety Inventory (STAI), Food Stop Signal Task (SST), the Emotional Eating Scale (EES).

Results: Abdominal obesity women had significantly higher levels of trait anxiety, cognitive difference, expectational difference in body image but lower self-reported emotional eating level compared to the control group. Anxiety mediated the relationship between cognitive difference of body image and depression eating in young females with abdominal obesity. In addition, only among abdominal obesity individuals, expectational difference of body image were significantly and positively correlated with food-specific inhibitory control and trait/state anxiety.
\end{abstract}

Conclusion: The findings suggest it is of critical importance to promote a healthy body image recognition and expectation and improve mood regulation for young females with abdominal obesity high in trait anxiety.

Keywords: Body image, Anxiety, Food-specific inhibitory control, Emotional eating, Abdominal obesity, Young women

\section{Background}

Abdominal fat deposition is a key component of obesity [1]. Some studies have shown that abdomen circumference (AC) may be a better predictor for the risk of type 2 diabetes, medical care costs, and all-cause mortality than body mass index (BMI) [2-5]. Abdominal obesity are characterized with excessive body fat in abdomen circumference [6]. The prevalence of visceral fat that

*Correspondence: syp.grape@163.com

School of Journalism and New Media, Xi'an Jiaotong University, Xi'an, China accumulates around abdominal organs is increasing worldwide [7, 8]. Visceral fat cells have an crucial impact on overall health and well-being. Inappropriate diets such as high-calorie foods are other main influential risk factors for increasing abdominal obesity. Consequently, $\mathrm{AC}$ has emerged as a candidate for assessing abdominal obesity. In fact, AC has been reported to predict mortality risk better than BMI [9]. The AC is positively correlated with the abdominal fat. Hence, the AC is a valuable, convenient and a simple measurement method which can be

(c) The Author(s). 2021 Open Access This article is licensed under a Creative Commons Attribution 4.0 International License, which permits use, sharing, adaptation, distribution and reproduction in any medium or format, as long as you give appropriate credit to the original author(s) and the source, provide a link to the Creative Commons licence, and indicate if changes were made. The images or other third party material in this article are included in the article's Creative Commons licence, unless indicated otherwise in a credit line to the material. If material is not included in the article's Creative Commons licence and your intended use is not permitted by statutory regulation or exceeds the permitted use, you will need to obtain permission directly from the copyright holder. To view a copy of this licence, visit http://creativecommons.org/licenses/by/4.0/ The Creative Commons Public Domain Dedication waiver (http://creativecommons.org/publicdomain/zero/1.0/) applies to the data made available in this article, unless otherwise stated in a credit line to the data. 
used for identifying the individuals who are at an increased risk for the above mentioned diseases. The identification of the abdominal obesity by the abdomen circumference measurement is easily accessible and should become the obligatory part of any physical examination [10]. AC, frequently used as a simple, inexpensive measure of central obesity in population-based studies, has been shown to be associated with depression in some studies [11].

Eating behaviors, negative emotions (i.e., anxiety and angry), inhibitory control, and body image perception are implicated in the multifactorial psychological factors of obesity [12-16]. Obesity has been associated with an increased lifetime risk for major depression and panic disorder or agoraphobia, particularly among females [17]. They always use food to cope with stress and emotions. Eating has been recognized as a coping mechanism for alleviating and dealing with stress and emotions [18] by either undereating or overeating [19].

Body image has been demonstrated to be associated with obesity either as a cause or as a result that impacts on weight control behaviors [20, 21]. Perceptual body size misperception (either underestimation or overestimation) occurs more in individuals with greater obesity, and it can potentially lead to a lesser awareness of the health risks associated with obesity and a reduction in the implementation of weight control behaviors such as dieting [22].

Altered inhibitory control has been implicated in obesity. Several studies concluded that obesity and bingerelated eating disorders (EDs) are associated with poor inhibitory control $[23,24]$. The stop signal task (SST) was chosen as it is commonly used to assess motor control, with cognitive underpinnings that are clearly established and may have relevance to eating and weight-control behaviors (e.g., cognitive control exercised when resisting urges to eat) [25]. However, in both adults and youth, the findings were largely inconsistent. Three studies reported greater SSRTs (Stop Signal Reaction Time) in obese adults and overweight individuals $[26,27]$. In contrast, some studies found no overall differences in SSRT between normal weight groups and overweight/ obese adults [26, 28-31].

Emotional eating has been observed in both obese individuals [32] and a critical review of the literature concluded that there is no relationship between body mass index and emotional eating [33]. Thus, vulnerability to emotional eating does not appear to be simply a function of weight. Emotional eating is likely effected by other psychological factors. Dysfunctional eating behaviors appeared to correlate strongly with body dissatisfaction, and perfectionism in girls [34]. In addition to body image, individual differences in affective traits and states may account for some of the observed variability in the effects of emotions on eating [35].
Several studies have found that obesity were more concerned about their physical appearance (body dissatisfaction and obsession with being thin) [36]. In fact, some authors argue that these types of cognitive variables could explain the vulnerability shown in people who go on to develop an eating disorder [37]. Likewise, common mental disorders were associated with an increased risk of obesity, and that the risk of obesity increased with the number of episodes of anxiety [38]. To be more specific, several studies have shown that youths who feel bad physically also feel bad emotionally [39]. Jansen et al. [40] reported that obese individuals high in negative affect consumed more food-specific than individuals low in negative affect following a negative mood induction, relative to a neutral mood induction. In contrast, lean individuals consumed comparable amounts of calories in the negative and neutral mood induction conditions, regardless of their level of negative affect [40]. With regard to this question, Braet et al. [41] point out that different psychological mechanisms and patterns seem to be in place in obesity female versus the control group. Considering the conclusion that high trait anxiety was positively associated with food-specific intake for obese individuals, but not their lean counterparts [35], it was possible to infer that the obesity group is more vulnerable to developing eating disorders, as those obesity female generally show more body image dissatisfaction, worse food-specific inhibition, and higher levels of anxiety regarding their body and weight and follow unhealthy diet administration. Therefore, anxiety is inferred to be the psychological mechanisms and patterns of of inappropriate emotional eating in obese youths [42].

More than half of the females preferred their ideal figure to be underweight, whereas about 30\% males chose an overweight figure as their ideal model. Females were generally more concerned about body weight, body shape and eating than males. As suggested in the aforementioned studies, obesity female may be significant risk conditions, especially in youth, associated with inappropriate weight-control behaviors, emotional distress (anxiety, depressive symptoms, etc.) and concerns about one's own body image (body dissatisfaction, negative beliefs about one's body and eating, etc.) [43]. In addition, in China, despite having high obesity prevalence rates and more serious abdominal obesity prevalence rates [44-46], no studies have been carried out to analyse body image dissatisfaction, inappropriate emotional eating behaviors, food-specific inhibitory control and their relationship with variables of emotional distress according to whether they are abdominal obesity. In addition to state anxiety, trait anxiety may also be a risk factor for emotional eating among obese individuals [35]. 
Although the prevalence of overall obesity as measured by BMI is well-documented and it has increased dramatically in the past 2 decades [47, 48], little is known about the psychological characteristics of abdominal obesity in young women. Taking these into account, The present study established the following objectives: (a) to compare the level of inhibitory control, emotional eating, anxiety and body image between abdominal obesity and nonabdominal obesity in young women, (b) to compare abdomen circumference -related differences in relation between the level of inhibitory control, emotional eating, anxiety and body image in abdominal obesity and nonabdominal obesity groups, (c) to test the hypothesis that anxiety is the psychological mechanisms and patterns of of inappropriate emotional eating in obese youths.

\section{Methods and materials Study design}

A comparative crossectional study approach was used.

\section{Participants}

Xi'an was the place where this study was conducted. It is an important central city in western of China. The study was run beginning from May 2th, to October 20nd, 2019. All the participants were recruited through advertisements at local universities. They were selected by convenient sampling to participate in anonymous questionnaires survey and behavioral experimental tasks. The inclusion criteria were; being aged 18-25. In this study, the term 'young women' refers to the study population at hand with individuals aged 18-25. Young women were excluded from the study when the target individuals had a serious handicap, visual impairment, chronic neurological disorder (e.g., mental retardation), or psychiatric disorder.

The sample consisted of 224 young women who signed an informed consent. Of the 224 participants, $25 \%$ were abdominal obesity individuals (Non-abdominal Obesity: 168, abdomen circumference $\leq 85 \mathrm{~cm}$; Abdominal Obesity: 56, abdomen circumference $\geq 85 \mathrm{~cm}$ ) [49]. They studied in college in Xi'an city and received small presents for their participation. None reported significant medical impairments or physical and mental illness.

\section{Procedure}

These female youth accepted tests in a quiet room individually. They completed tasks in a fixed order: demographic, height, weight and body image perceptions (the body mass index -based Silhouette-Matching Test), anxiety (state-trait anxiety inventory), Food- inhibitory control (the Food- Stop Signal Task), emotional eating (the Emotional Eating Scale). Each measure is described in detail in the following section.

\section{Measures}

\section{Body image perceptions}

Body image attitude was measured by the body mass index (BMI)-based Silhouette-Matching Test (SMT; [50]). In this test, participants were presented with silhouettes of figures ranging from very slim to very full, and were required to choose a number below the figures (1 to 27) to indicate (a) their current figure, (b) the ideal figure which they would like to have. In the current study, participants' selection of the current figure was significantly correlated with current BMI, as calculated from a participant's reported height and weight $(r=.74$, $p<.001, \mathrm{df}=224)$. The degree of body image dissatisfaction was quantified with two measures: (1) Cognitive difference of body image (Cognitive 27-point SMT-BMI): the absolute value of this difference as some individuals may prefer a fuller image of themselves; and (2) Expectational difference of body image (Cognitive 27-point SMTExpectational 27-point SMT): the difference between current and ideal body image (subjective drive for thinness). Similar methods have been used previously [51].

\section{Anxiety}

Levels of anxiety were measured with the Chinese version of the State-Trait Anxiety Inventory (STAI) SAnxiety Scale $[52,53]$. There are 2 subscales within this measure. The State Anxiety Scale (S-Anxiety) evaluates the current state of anxiety, asking how respondents feel "right now," using items that measure subjective feelings of apprehension, tension, nervousness, worry, and activation/ arousal of the autonomic nervous system. The Trait Anxiety Scale (T-Anxiety) evaluates relatively stable aspects of "anxiety proneness," including general states of calmness, confidence, and security. The STAI has 40 items, 20 items allocated to each of the S-Anxiety and T-Anxiety subscales. All items are self-rated on a 4point scale of $1=$ not at all, $2=$ somewhat, $3=$ moderately and $4=$ very much, and they are added to obtain a total score for each respondent. Total scores range from 20 to 80, with higher scores indicating higher levels of anxiety. The scale has been tested and validated for the Chinese context. The Cronbach's alpha level was acceptable (.82 and 0.79).

\section{Food- inhibitory control}

In the Food-stop signal task [27, 54], participants need to classify continuously presented stimuli according to simple criteria by key press. A stop signal is presented unpredictably in a random subset of trials following the display of the imperative stimulus and before the anticipated response. Participants are instructed not to execute the response in these trials. The paradigm is based on the theoretical horse-race model 55], which assumes independent go- and stop-processes. If the stop-process 
terminates before the go-process, a response is effectively inhibited. Good stopping performance is reflected in a fast stop-process which can be initiated late and which will, therefore, still terminate an ongoing response tendency. Participants were instructed to select as quickly and accurately as possible on which side the picture appeared by pressing either a left or a right response button. In the low calorie and high calorie foodstop signal task, there were respectively 3 kinds of photographs of shapes (e.g., quadrate, roundness, etc.), lowcalorie food items (e.g., tomato, apples, etc.) and high calorie food items (e.g., fried chickens, desserts, etc.). A picture appeared in either on the left or right side of the fixation cross. A left or a right response button respectively represents a response to specific stimulus. In stop trials, a small blueberry /doughnut appeared over the picture as the stop signal after a variable delay. Upon any response detected or after $1500 \mathrm{~ms}$, the screen was cleared. The recorded scores reflected "stop" accuracy in stop trials. The dependent variable, stop signal reaction time (SSRT), was calculated by subtracting the mean stop delay from mean reaction times. Higher SSRTs indicate decreased inhibitory control. Higher stop signal accuracy (SSACC) indicated better performance.

\section{Emotional eating}

The emotional eating scale [56] has been used to investigate eating behavior in response to negative emotions. We used the Chinese version of the Emotional Eating Scale [57], which contains four factors: eating in response to anxiety (four items), depression (nine items), anger/hostility (five items) and positive emotion (five items). Participants were asked to respond to questions about their desire to eat when experiencing certain emotions (e.g., "Do you have a desire to eat when you are sad, irritated, worried, or lonely?") on a 5-point Likert scale ranging from 1 (never) to 5 (very strong). Higher scores indicate a stronger desire to eat. In the current study, Cronbach's $\alpha$ was 0.73 (anxiety) -0.80 (anger/hostility) for each emotional eating scale.

\section{Covariates}

We adjusted for age, BMI, family socioeconomic status (SES). Although ideally, all participants should have provided information including all three components (education, occupation, and income) of SES, the majority of students, especially in China, only know and are more willing to provide information about education and occupation than income data [58]. Therefore, our study only considered the education and occupational prestige of participants' parents. These were assigned based on categories of the Hollingshead Index matched as closely as possible to modern education and occupation status [59]. The family SES composite index was the sum value of parents' SES.

\section{Statistical analysis}

The descriptive statistics, correlations and path analysis were computed using SPSS 16.0 and AMOS 7.0 software [60]. Depending on the scale of the variable, the mean, standard deviations, and proportions were presented as a descriptive summary. And a comparison of the abdominal obesity and non-abdominal obesity groups was conducted through independentsamples $t$ test. Two separate correlation analysis were run. Partial correlations was used to assess whether there are association differences of inhibitory control, emotional eating, anxiety and body image between abdominal obesity and non-abdominal obesity in young women.

Mediation tests indicated whether the association between two variables resulted from another variable or a set of variables. Path analysis is a specific tool of the structural equation model (SEM) analysis to analyze assumed relationships of multivariate data. Mediation tests were computed using path analysis in AMOS 7.0 with maximum likelihood estimation to examine the significance of the direct effects of cognitive difference of body image on depression eating in the female abdominal obesity group, mediated through the anxiety. The structural equation model as illustrated (see Fig. 1) was tested for indirect effects of anxiety with a biascorrected bootstrapping procedure based on 2000

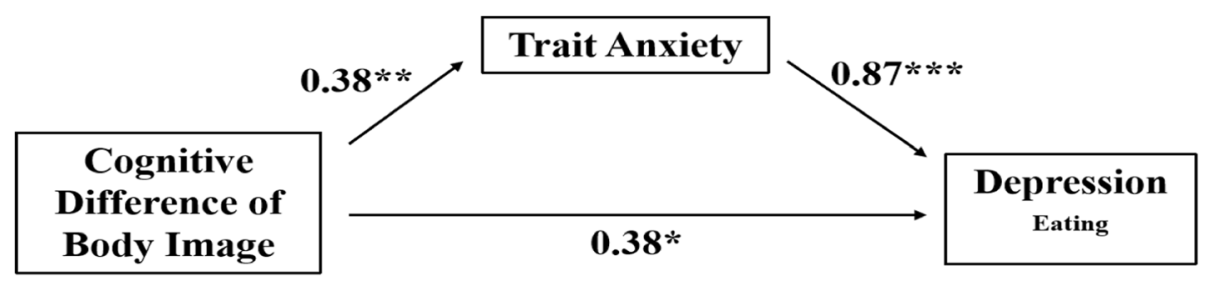

Fig. 1 Trait anxiety mediation effects in the relationships between cognitive difference of body image and depression eating in the female abdominal obesity group controlling for age, BMI, and family SES. Significant paths from cognitive difference of body image to depression eating (using bias-corrected bootstrapped confidence intervals). Mean path coefficients were obtained using 2000 bootstrap samples. Note. ${ }^{*} p<.05 .{ }^{* *} p<.01 .{ }^{* * *} p<.001$ 
bootstrap samples to estimate standardized regression estimates. For a good fit, the degrees of freedom $\left(x^{2} /\right.$ df) should be as small as possible, and values less than three indicate a good or acceptable fit. Goodness of fit indices were assessed based on following criteria: Tucker Lewis index (TLI) and comparative fit index (CFI) close to 0.9 and Root Mean Square Error of Approximation (RMSEA) $<0.8$ [61].

\section{Results}

Body image, anxiety, food- inhibitory control and emotional eating

Cognitive difference and expectational difference of body image were greater than zero. All the participants (100\%) perceived themselves to be fatter than physical truth and wanted a more slender figure. Participants of both groups were equivalent in age. However, no significant difference between the groups with respect to the stop signal accuracy (shape, low calorie, high calorie food), the stop signal reaction time (shape, low calorie, high calorie food), depression eating and anger/hostility eating. Abdominal obesity female youths reported higher levels of cognitive difference and expectational difference of body image $(t=-2.05, p<.01 ; t=-11.19, p<.001)$, while non-abdominal obesity ones reported higher emotional eating scores about anxiety eating and positive emotion eating $(t=3.46, p<.01 ; t=4.34, p<.01)$ (Table 1$)$.
Partial correlations between body image, anxiety and the stop signal task

Partial correlation analysis showed that for abdominal obesity female youths (abdomen circumference $\geq 85 \mathrm{~cm}$ ), the correlation between expectational difference of body image, trait anxiety, state anxiety, SSACC $\mathrm{Low}_{\text {Calorie, and }}$ SSACC $_{\text {High Calorie were significant }}(r=.59, p<.001 ; r=$ $.47, p<.001 ; r=.32, p<.05 ; r=.40, p<.01 ;)$. For nonabdominal obesity ones (abdomen circumference $\leq 85$ $\mathrm{cm}$ ), the correlation between cognitive difference of body image, SSACC Low Calorie, and SSACC High Calorie were significant $(r=.18, p<.05 ; r=.23, p<.01)$. However, the correlation between expectational difference of body image, trait anxiety, SSACC Low Calorie, and SSACC High Calorie were not significant. For non-abdominal obesity ones, the correlation between body image and most emotional eating scores were negatively correlated. On the contrary, in the abdominal obesity group, the correlation between cognitive difference of body image, expectational difference of body image and depression eating were positively correlated $(r=.41, p<.01 ; r=.28$, $p<.05$ ) (Table 2).

Partial correlations between anxiety and emotional eating As presented in Table 3, overall trait anxiety and state anxiety was correlated with depression eating and anger/ hostility eating. Analyzing by non-abdominal obesity \& abdominal obesity separately, partial correlations between

Table 1 Body Image, Anxiety, Food- inhibitory Control and Emotional Eating of Two Abdomen Circumference Groups

\begin{tabular}{|c|c|c|c|c|}
\hline & $\begin{array}{l}\text { Non-abdominal } \\
\text { Obesity }(n=168)\end{array}$ & $\begin{array}{l}\text { Abdominal } \\
\text { Obesity }(n=56)\end{array}$ & $t$ value & $p$ value \\
\hline Age & $20.56(0.86)$ & $21.02(1.02)$ & 0.76 & 0.40 \\
\hline $\mathrm{BMI}$ & $20.44(1.95)$ & $25.33(0.93)$ & -14.26 & $* * *$ \\
\hline Family SES & $54.19(18.27)$ & $60.71(27.87)$ & -0.20 & * \\
\hline Body Image CD & $6.13(2.88)$ & $7.03(2.63)$ & -2.05 & $* *$ \\
\hline Body Image ED & $4.07(3.74)$ & $8.14(1.65)$ & -11.19 & $* * *$ \\
\hline Trait Anxiety & $38.00(7.90)$ & $40.36(8.08)$ & -1.82 & $0.07^{\dagger}$ \\
\hline State Anxiety & $40.62(8.43)$ & $42.79(8.26)$ & -1.77 & $0.08^{\dagger}$ \\
\hline SSACC Shape & $0.52(0.06)$ & $0.53(0.05)$ & -0.97 & 0.34 \\
\hline SSRT Shape (ms) & $505.23(80.62)$ & $489.31(85.19)$ & 1.26 & 0.21 \\
\hline SSACC Low Calorie & $0.58(0.06)$ & $0.59(0.05)$ & -1.00 & 0.32 \\
\hline SSRT Low Calorie (ms) & $581.27(85.91)$ & $597.50(89.51)$ & -1.21 & 0.23 \\
\hline SSACC High Calorie & $0.57(0.06)$ & $0.57(0.06)$ & -0.57 & 0.57 \\
\hline SSRT High Calorie (ms) & $569.63(84.23)$ & $580.77(96.51)$ & -0.77 & 0.41 \\
\hline Depression Eating & $2.15(0.69)$ & $2.19(0.89)$ & -0.28 & 0.78 \\
\hline Anxiety Eating & $1.76(0.48)$ & $1.50(0.53)$ & 3.46 & $* *$ \\
\hline Anger/Hostility Eating & $1.73(0.54)$ & $1.60(0.52)$ & 1.62 & 0.11 \\
\hline Positive emotion Eating & $3.44(0.86)$ & $3.01(0.55)$ & 4.34 & ** \\
\hline
\end{tabular}

Note. SES Socioeconomic status, CD Cognitive Difference, SSACC Expectational Difference; the stop signal accuracy, SSRT the stop signal reaction time; ${ }^{\dagger} p<.10$. ${ }^{*} p<.05 .{ }^{* *} p<.01$. $^{* * *} p<.001$ 


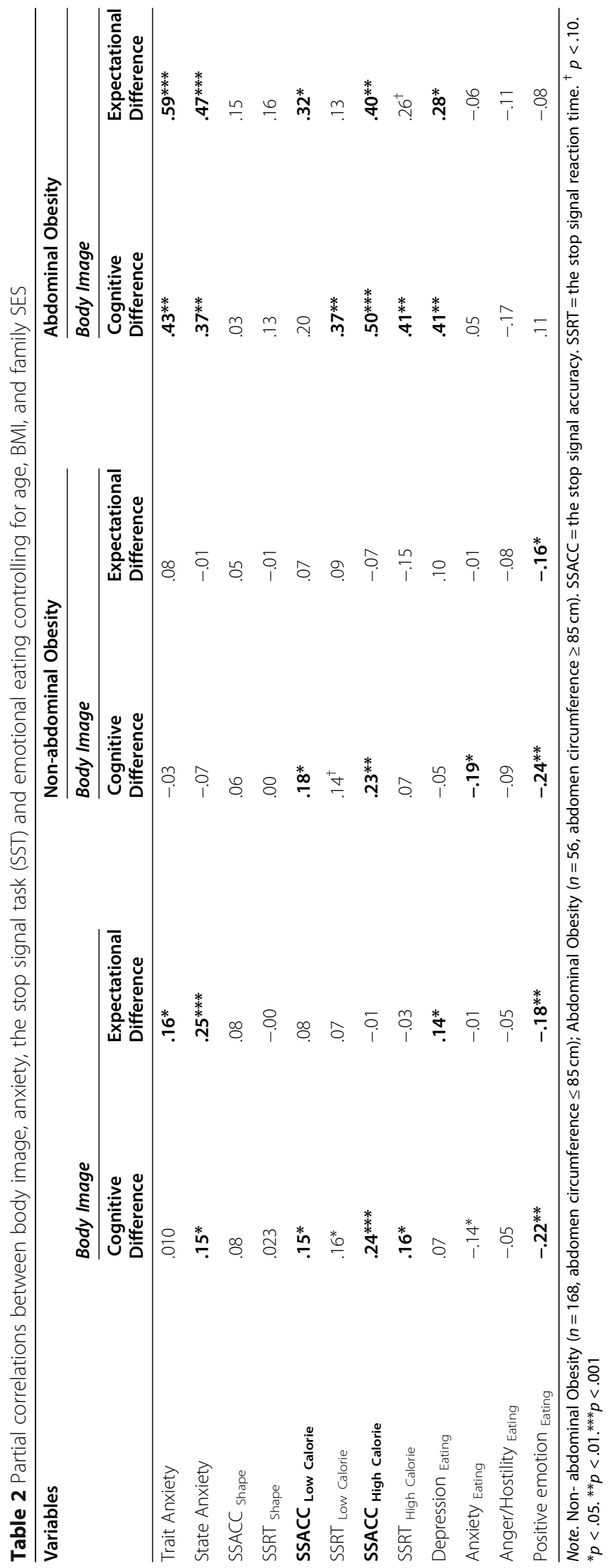


Table 3 Partial correlations between anxiety and emotional eating controlling for age, BMI, and family SES

\begin{tabular}{|c|c|c|c|c|c|c|}
\hline \multirow[t]{2}{*}{ Variables } & \multirow[b]{2}{*}{ Trait Anxiety } & \multirow[b]{2}{*}{ State Anxiety } & \multicolumn{2}{|c|}{ Non-abdominal Obesity } & \multicolumn{2}{|c|}{ Abdominal Obesity } \\
\hline & & & Trait Anxiety & State Anxiety & Trait Anxiety & State Anxiety \\
\hline Depression Eating & $.23^{* * *}$ & $.14^{*}$ & .07 & -.01 & $.58^{* * *}$ & $.51 * * *$ \\
\hline Anxiety Eating & $.16^{*}$ & $.12^{\dagger}$ & .13 & .07 & $.33^{*}$ & $.27^{\dagger}$ \\
\hline Anger/Hostility Eating & $.23^{* *}$ & $.14^{*}$ & $.19^{*}$ & .12 & $.23^{\dagger}$ & .13 \\
\hline Positive emotion Eating & .02 & .00 & .08 & .06 & -.20 & -.15 \\
\hline
\end{tabular}

Note. Non- abdominal Obesity $(n=168$, abdomen circumference $\leq 85 \mathrm{~cm})$; Abdominal Obesity $(n=56$, abdomen circumference $\geq 85 \mathrm{~cm}) .{ }^{\dagger} p<.10$. ${ }^{*} p<.05 .{ }^{* *} p<.01 .{ }^{* *} p<.001$

trait anxiety, state anxiety and depression eating were significant $(r=.58, p<.001 ; r=51, p<.001)$ for abdominal obesity female undergraduates. And partial correlations between trait anxiety and anxiety eating were also significant $(r=.33, p<.05)$. In a parallel analysis of the nonabdominal obesity group, only the correlation between trait anxiety and anger/hostility eating was significant $(r=.19, p<.05)$.

\section{Mediation results}

The structural equation model provided a good fit to the sample data with TLI $=.98, \mathrm{CFI}=0.94, \mathrm{RMSEA}=.00, \chi^{2}$ / $d f=.88$. Cognitive difference of body image predicted the mediating variables trait anxiety and state anxiety $(\beta=.38,95 \%$ CI: $0.10-0.62, p<.01 ; \beta=.50,95 \%$ CI: $0.21-0.74, p<.01)$. There was significant direct influence of cognitive difference of body image $(\beta=.38,95 \% \mathrm{CI}$ : $0.05-0.71, p<.05)$, as the predicted variable, on depression eating. As predictive indirect effect of mediating variables in cognitive difference of body image on depression eating, only trait anxiety $(\beta=.87,95 \% \mathrm{CI}$ : $0.03-0.21, p<.001)$ had indirect influences on the relationship between cognitive difference of body image and depression eating in the female abdominal obesity group (see Fig. 1). There was significant direct influence of SES $(\beta=.39,95 \%$ CI: $0.14-0.61, p<.01)$, as the covariate, on depression eating.

\section{Discussion}

The prevalence of abdominal obesity among Chinese adults was $37.4 \%$ (45.9\% in females) according to the China Health and Nutrition Surveys in 2009 [62]. This study reported that the prevalence of abdominal obesity (defined as abdomen circumference $\geq 85 \mathrm{~cm}$ for females) was $25 \%$ for female college student, which showed a trend towards a lower prevalence of abdominal obesity compared to those in other studies [63]. There may be two aspects related to this difference in prevalence. On the one hand, the values of the reference standards were different. On the other hand, age ranges are different. The increase was larger among individuals between the ages of 40 and 59 years [62], which suggests that the prevalence of young female abdominal obesity among the subpopulation of 19-23 with a higher level of education was lower.

In this study, all the participants (100\%) perceived themselves to be fatter than physical truth and wanted a more slender figure. Indeed, wanting a thinner image was a general trend. The differences and the AC-related differences in relation of inhibitory control, emotional eating, anxiety and body image between abdominal obesity and non-abdominal obesity in young women were compared. Abdominal obesity female youths and nonabdominal obesity ones showed statistically significant differences in body image (cognitive difference and expectational difference), anxiety (trait anxiety and state anxiety), which has already been seen in previous studies $[36,40]$. In all SST measure variables, no statistically significant differences were found between two groups. These results are consistent with previous researches about female undergraduates motivated to manage weight and they found no correlation between SSRT in food trials, other any SST measure and BMI [64-66]. Contrary to our hypothesis, non-abdominal obesity female obtained higher scores in emotional eating variables, especially anxiety eating and positive emotion eating. One reason may be that self-reported emotional eating is not related to greater food intake $[67,68]$. People may be considerably biased in their ability to identify themselves as emotional eaters [69-71], whether they are fat or not. These results lead us to think that self-reported emotional eating measure may actually reflect eating concerns [70].

Interestingly, cognitive difference of body image have been associated with the SST, including SSACC Low Calorie, SSRT Low Calorie, SSACC High Calorie, and SSRT High Calorie in all participants and non-abdominal obesity group. However, in the abdominal obesity group, the expectational difference of body image also positively associated with SSACC Low Calorie and SSACC High Calorie. This means that food- specific inhibitory control variables, especially SSACC High Calorie, only tends to be affected by expectational body image in abdominal obesity female groups. One possible explanation is that the abdominal obesity individuals desire to be thinner, but all the females often considered themself fatter than 
current body shape. One's appearance is becoming increasingly important in modern society [72]. Hence, more normal body shape girls perceived themselves to be fatter than current body shape [73].

Results revealed that cognitive difference of body image is positively associated with emotional eating for female abdominal obesity individuals, but not for their non-abdominal obesity counterparts, in which cognitive difference of body image is negatively associated with emotional eating. Given prior findings linking body image dissatisfaction to obesity [74] and emotion to obesity risk [75], this study suggests the need for additional research on the potential mediating mechanisms linking these factors. In other words, one potential explanation for the discrepancy between the effects of cognitive difference of body image on emotional eating relates to whether these relationships are mediated by some other emotion. Emotional eating is more commonly reported by women than men [76], and it is often triggered by anxiety [77]. A potential mediating mechanism is anxiety given that social physique anxiety has been observed in individuals with body image dissatisfaction to obesity [78].

Our finding that emotional eating was linked to trait and state anxiety may reflect the fact that anxiety involves the avoidance motivational system and is subject to regulation by strategies such as eating [35]. These results are in keeping with those obtained in studies by other author [40]. The results of this study show that obese individuals high in negative affect may consume more calories in response to a negative mood compared to obese individuals low in negative affect, and to lean individuals. An important finding of this study was that trait and state anxiety mediated the relationship between cognitive difference of body image and depression eating in female abdominal obesity individuals. Our studies could help elucidate the role of cognitive difference of body image in vulnerability to emotional eating among female abdominal obesity individuals with high anxiety.

This study has several limitations worth noting. First, the study was limited by its cross-sectional design and cause-effect relationships could not be established. Therefore, future studies using a longitudinal design will be required to clarify the direction of these associations. Second, emotional eating was collected from female youths using self-report questionnaires. It remains a possibility that people are unable to accurately report on their own emotional eating behaviour [79]. An alternative to self-report questionnaires as the criterion for emotional eating is to use a highly valid experimental food paradigm. Third, a convenient sample of students was used in the present study due to the complexity and particularity of the Food- inhibitory control testing process and the constraints of both financial and human resources. This sample was comprised purely of students from Xi'an of Shaanxi province, likely representing a collectivistic culture.

\section{Conclusion}

Results demonstrated that anxiety mediated the relationship between cognitive difference of body image and depressed eating in young females with abdominal obesity. In addition, only among abdominal obesity individuals, expectational difference of body image were significantly and positively correlated with food-specific inhibitory control and trait/state anxiety. The findings suggest it is of critical importance to promote a healthy body image recognition and expectation and improve mood regulation for young females with abdominal obesity high in trait anxiety.

\section{Abbreviations \\ BMI: Body Mass Index; SMT: Silhouette-Matching Test; STAI: State-Trait Anxiety Inventory; SST: Stop Signal Task; EES: Emotional Eating Scale; AC: Abdomen Circumference; EDs: Eating Disorders; SSRT: Stop Signal Reaction Time}

\section{Acknowledgements}

We would like to thank the study participants for their time and effort.

Authors' contributions

All authors made significant contributions to the paper. $\mathrm{ZHH}$ and MDL identified the research question and designed the study. Data collection and analysis were carried out by $(\mathrm{ZHH})$ and then discussed and revised with all authors ( $\mathrm{ZHH}, \mathrm{MDL}, \mathrm{CJ}$, and $\mathrm{XYM})$. All authors ( $\mathrm{ZHH}, \mathrm{MDL}, \mathrm{CJ}$, and $\mathrm{XYM}$ ) read and approved the final manuscript.

\section{Funding}

This work was supported by grants from Social Science Foundation of Shaanxi Province (2020 M007), China Postdoctoral Science Foundation (2020 M683444), and the Fundamental Research Funds for Xi'an Jiaotong University (SK2020019).

\section{Availability of data and materials}

The data used during the current study are available from the corresponding author on reasonable request.

Ethics approval and consent to participate

All procedures performed in studies involving human participants were in accordance with the ethical standards of Biomedical Ethics Committee of the Medical Department of Xi'an Jiaotong University. Informed consent was obtained from all individual participants included in the study.

Consent for publication

Written informed consent for publication was obtained from all participants.

\section{Competing interests}

The authors declare that they have no conflict of interest.

Received: 29 September 2020 Accepted: 4 January 2021

Published online: 25 January 2021

References

1. Sharma AM. Adipose tissue: a mediator of cardiovascular risk. Int J Obes Relat Metab Disord. 2002;26(supplement 4):S5 https://doi.org/10.1038/sj.ijo. 0802210.

2. Bigaard J, Frederiksen K, TjoNneland A, Thomsen BL, Overvad K, Heitmann $\mathrm{BL}$, et al. Waist circumference and body composition in relation to all-cause mortality in middle-aged men and women. Int J Obes. 2005;29(7):778-84 https://doi.org/10.1038/sj.ijo.0802976. 
3. Calderón C, Forns M, Varea V. Obesidad infantil: ansiedad y síntomas cognitivos y conductuales propios de los trastornos de alimentación. Anales de Pediatría. 2009;71(6):489-94 https://doi.org/10.1016/j.anpedi.2009.07.030.

4. Cornier MA, Tate CW, Grunwald GK, Bessesen DH. Relationship between waist circumference, body mass index, and medical care costs. Obes Res. 2002;10(11):1167-72 https://doi.org/10.1038/oby.2002.158.

5. Rimm EB, Hu FB, Stampfer MJ, Willett WC, Wang Y. Comparison of abdominal adiposity and overall obesity in predicting risk of type 2 diabetes among men. Am J Clin Nutr. 2005;81(3):555-63 https://doi.org/10.1556/ AAlim.34.2005.1.12.

6. Kumanyika SK, Obarzanek E, Stettler N, Bell R, Field AE, Fortmann SP, et al. Population-based prevention of obesity. Circulation. 2008;118(4):428-64 https://doi.org/10.1161/CIRCULATIONAHA.108.189702.

7. Pi-Sunyer FX. The epidemiology of central fat distribution in relation to disease. Nutr Rev. 2004; https://doi.org/10.1111/j.1753-4887.2004.tb00081.x.

8. Xi B. Secular trends in the prevalence of general and abdominal obesity among Chinese adults, 1993-2009. Obes Rev. 2012;13(3):287-96 https://doi. org/10.1111/j.1467-789x.2011.00944.x.

9. Kang SM, Yoon JW, Ahn HY, Kim SY, Lee KH, Shin H, et al. Android fat depot is more closely associated with metabolic syndrome than abdominal visceral fat in elderly people. PLoS One. 2011;6:e27694 https://10.1371/ journal.pone.0027694.

10. Sucharda P. Abdominal obesity. Cas Lek Cesk. 2009;148(2):78-82.

11. Moreira RO, Marca KF, Appolinario JC, Coutinho WF. Increased waist circumference is associated with an increased prevalence of mood disorders and depressive symptoms in obese women. Eat Weight Disord. 2007;12(1):35-40 https://doi.org/10.1007/BF03327770.

12. Heo M, Pietrobelli A, Fontaine KR, Sirey JA, Faith MS. Depressive mood and obesity in us adults: comparison and moderation by sex, age, and race. Int J Obes. 2006;30(3):513-9 https://doi.org/10.1038/sj.ijo.0803122.

13. Kang MH, Choue R. Relationships of body image, body stress and eating attitude, and dietary quality in middle school girls based on their BMI. Korean J Nutr. 2010;43(3) https://doi.org/10.4163/kjn.2010.43.3.285

14. Strine TW, Mokdad AH, Dube SR, Balluz LS, Gonzalez O, Berry JT, et al. The association of depression and anxiety with obesity and unhealthy behaviors among community-dwelling us adults. Gen Hosp Psychiatry. 2008;30(2):12737 https://doi.org/10.1016/j.genhosppsych.2007.12.008.

15. Sutter C, Ontai L, Scherr R, Linnell J, Nicholson Y, Spezzano T, et al. Individual differences in associations between parenting practices and BMl: the role of inhibitory control. J Nutr Educ Behav. 2014;46(4):S136 https://doi. org/10.1016/j.jneb.2014.04.104.

16. Zhao G, Ford ES, Dhingra S, Li C, Strine TW, Mokdad AH. Depression and anxiety among us adults: associations with body mass index. Int J Obes, (2005). 2009;33(2):257-66 https://doi.org/10.1038/ijo.2008.268.

17. Anderson SE, Cohen P, Naumova EN, Must A. Association of depression and anxiety disorders with weight change in a prospective community-based study of children followed up into adulthood. Arch Pediatr Adolesc Med. 2006;160(3):285 https://doi.org/10.1001/archpedi.160.3.285.

18. Solomon MR. Eating as both coping and stressor in overweight control. J Adv Nurs. 2001;36(4):563-72 https://doi.org/10.1046/j.1365-2648.2001.02009. $x$.

19. Geliebter A, Aversa A. Emotional eating in overweight, normal weight, and underweight individuals. Eat Behav. 2003;3(4):341-7 https://doi.org/10.1016/ S1471-0153(02)00100-9.

20. Flynn KJ, Fitzgibbon M. Body images and obesity risk among black females: a review of the literature. Ann Behav Med. 1998;20(1):13-24 https://doi.org/ $10.1007 /$ bf02893804.

21. Gilbert-Diamond D, Baylin A, Mora-Plazas M, Villamor E. Correlates of obesity and body image in colombian women. J Women's Health. 2009;18(8):1145 https://doi.org/10.1089/jwh.2008.1179.

22. So ES. Perceptual body image and the relationship with weight control across the adult lifespan by sex in Koreans. J Public Health. 2017;39(4):77786 https://doi.org/10.1093/pubmed/fdx021.

23. Liang J, Matheson B, Kaye W, Boutelle K. Neurocognitive correlates of obesity and obesity-related behaviors in children and adolescents. Int J Obes. 2014;38:494-506 https://doi.org/10.1038/ijo.2013.142.

24. Reinert KRS, Pe EK, Barkin SL. The relationship between executive function and obesity in children and adolescents: a systematic literature review. J Obes. 2013;82095:6 https://doi.org/10.1155/2013/820956.

25. Bartholdy S, Dalton B, O'Daly OG, Campbell IC, Schmidt U. A systematic review of the relationship between eating, weight and inhibitory control using the stop signal task. Neurosci Biobehav Rev. 2016;64:35-62 https://doi. org/10.1016/j.neubiorev.2016.02.010.

26. Chamberlain SR, Derbyshire KL, Leppink E, Grant JE. Obesity and dissociable forms of impulsivity in young adults. CNS Spectr. 2015;20:1-8 https://doi. org/10.1017/S1092852914000625.

27. Houben K, Nederkoorn C, Jansen A. Eating on impulse: the relation between overweight and food-specific inhibitory control. Obesity (Silver Spring). 2014;22:E6-8 https://doi.org/10.1002/oby.20670.

28. Grant J, Derbyshire K, Leppink E, Chamberlain S. Obesity and gambling: neurocognitive and clinical associations. Acta Psychiatr Scand. 2015;131: 379-86 https://doi.org/10.1111/acps.12353.

29. Hendrick OM, Luo X, Zhang S, Li CS. Saliency processing and obesity: a preliminary imaging study of the stop signal task. Obesity. 2012;20:1796-802 https://doi.org/10.1038/oby.2011.180.

30. Lawyer SR, Boomhower SR, Rasmussen EB. Differential associations between obesity and behavioral measures of impulsivity. Appetite. 2015;95:375-82 https://doi.org/10.1016/j.appet.2015.07.031.

31. Nederkoorn C. Effects of sales promotions, weight status, and impulsivity on purchases in a supermarket. Obesity. 2014;22:E2-5 https://doi.org/10.1002/ oby.20621.

32. Greeno CG, Wing RR. Stress-induced eating. Psychol Bull. 1994;115(3):444-64 https://doi.org/10.1037/0033-2909.115.3.444.

33. Allison DB, Heska S. Emotion and eating in obesity? A critical analysis. Int J Eating Disord. 1993;13(3):289-95 https://doi.org/10.1002/1098108x(199304)13:3<289::aid-eat2260130307>3.0.co;2-x.

34. Teixeira MD, Pereira AT, Marques MV, Saraiva JM, de Macedo António F. Eating behaviors, body image, perfectionism, and self-esteem in a sample of Portuguese girls. Rev Bras Psiquiatr. 2016;38(2):135-40 https://doi.org/10. 1590/1516-4446-2015-1723.

35. Schneider KL, Appelhans BM, Whited MC, Oleski J, Pagoto SL. Trait anxiety, but not trait anger, predisposes obese individuals to emotional eating. Appetite, (APPET). 2010;55(3):701-6 https://doi.org/10.1016/j.appet.2010.10. 006.

36. Cooper M, Burrows A. Behav Cognit Psychother. 2001;29(2):143-9.

37. Stoeber J, Yang H. Physical appearance perfectionism explains variance in eating disorder symptoms above general perfectionism. Personal Individ Differ. 2015;86:303-7 https://doi.org/10.1016/j.paid.2015.06.032.

38. Atlantis E, Goldney RD, Wittert GA. Obesity and depression or anxiety. BMJ. 2009;339 https://doi.org/10.1136/bmj.b3868.

39. Vingilis ER, Wade TJ, Seeley JS. Predictors of adolescent self-rated health. Analysis of the national population health survey. Can J Public Health. 2002; 93(3):193-7 https://doi.org/10.1080/03014460110079455.

40. Jansen A, Vanreyten A, van Balveren T, Roefs A, Nederkoorn C, Havermans R. Negative affect and cue-induced overeating in non-eating disordered obesity. Appetite. 2008;51(3):556-62 https://doi.org/10.1016/j.appet.2008.04. 009.

41. Braet C, Beyers W, Goossens L, Verbeken S, Moens E. Subtyping children and adolescents who are overweight based on eating pathology and psychopathology. Eur Eat Disord Rev. 2012;20(4):279-86 https://doi.org/10. 1002/erv.1151.

42. Petry NM, Barry D, Pietrzak RH, Wagner JA. Overweight and obesity are associated with psychiatric disorders: results from the national epidemiologic survey on alcohol and related conditions. Psychosom Med. 2008;70(3):288-97 https://doi.org/10.1097/psy.0b013e3181651651.

43. Ball K, Burton NW, Brown WJ. A prospective study of overweight, physical activity, and depressive symptoms in young women. Obesity. 2008;17(1):6671 https://doi.org/10.1038/oby.2008.497.

44. Fu Q, Land KC. The increasing prevalence of overweight and obesity of children and youth in China, 1989-2009: an age-period-cohort analysis. Popul Res Policy Rev. 2015;34(6):901-21 https://doi.org/10.1007/s11113-0159372-y.

45. Hu L, Huang X, You C, Li J, Hong K, Li P, et al. Prevalence of overweight, obesity, abdominal obesity and obesity-related risk factors in southern China. PLoS One. 2017;12(9):e0183934 https://doi.org/10.1371/journal.pone. 0183934.

46. Reynolds K, Gu D, Whelton PK, Wu X, Duan X, Mo J, et al. Prevalence and risk factors of overweight and obesity in China. Obesity. 2007;15(1):10-8 https://doi.org/10.1038/oby.2007.527.

47. Li C, Ford ES, Mcguire LC, Mokdad AH. Increasing trends in waist circumference and abdominal obesity among u.s. adults. Obesity. 2007; 15(1):216 https://doi.org/10.1038/oby.2007.505. 
48. Wimmelmann CL, Lund R, Flensborg-Madsen T, Christensen U, Osler M, Mortensen EL. Associations of personality with body mass index and obesity in a large late midlife community sample. Obes Facts. 2018;11(2): 129-43 https://doi.org/10.1159/000487888.

49. Wang $L$, Sun N. Ps 11-48 impact of taurine supplementation on abdominal obesity high-normal blood pressure. J Hypertens. 2016;34:e347 https://doi. org/10.1097/01.hjh.0000500880.58252.70.

50. Peterson M, Ellenberg D, Crossan S. Body-image perceptions: reliability of a BMI-based Silhouette matching test. Am J Health Behav. 2003;27:355-63 https://doi.org/10.5993/AJHB.27.4.7.

51. Thompson JK, Heinberg LJ, Altabe MN, TantleffDunn S. Exacting beauty: theory, assessment, and treatment of body image disturbance. Washington, DC: American Psychological Association; 1999.

52. Julian LJ. Measures of anxiety: state-trait anxiety inventory (STAI), beck anxiety inventory (BAI), and hospital anxiety and depression scale-anxiety (HADS-A). Arthritis Care Res. 2011;63(supplement S11):S467-72 https://doi. org/10.1002/acr.20561.

53. Shek DTL. Reliability and factorial structure of the Chinese version of the state-trait anxiety inventory. J Psychopathol Behav Assess. 1988;10(4):303-17 https://doi.org/10.1007/bf00960624.

54. Svaldi J, Naumann E, Trentowska M, Schmitz F. General and food-specific inhibitory deficits in binge eating disorder. Int J Eat Disord. 2014;47(5):53442.

55. Logan GD, Cowan WB, Davis KA. On the ability to inhibit simple and choice reaction time responses: A model and a method. J Exp Psychol Hum Percept Perform. 1984;10(2):276-91.

56. Arnow B, Kenardy J, Agras WS. The emotional eating scale: the development of a measure to assess coping with negative affect by eating. Int J Eat Disord. 1995;18:79-90 http://dx.doi.org/0.1002/1098-108x(199507)1 8:1<79::aid-eat2260180109>3.0.co;2-v.

57. Zhu H, Cai T, Chen G, Zhang B. Validation of the emotional eating scale among Chinese undergraduates. Soc Behav Personal Int J. 2013;41(1):12334 https://doi.org/10.2224/sbp.2013.41.1.123.

58. Bornstein MH, Bradley RH. Socioeconomic status, parenting, and child development. Mahwah: Erlbaum; 2003.

59. Hollingshead AB. Four factor index of social status. New Haven: Yale University Press; 1975.

60. Arbuckle JL. Amos (version 7.0) [computer program]. Chicago: SPSS; 2006.

61. Hu L, Bentler PM. Cutoff criteria for fit indexes in covariance structure analysis: conventional criteria versus. Structural equation modeling. Struct Equ Model Multidiscip J. 1999;6(1):1-55.

62. Jansen $H J$, van Essen $P$, Koenen $T$, Joosten LAB, Netea MG, Tack CJ, Stienstra R. Autophagy Activity Is Up-Regulated in Adipose Tissue of Obese Individuals and Modulates Proinflammatory Cytokine Expression. Endocrinology. 2012;153(12):5866-74.

63. Wang H, Wang J, Liu MM, Wang D, Liu YQ, Zhao Y, et al. Epidemiology of general obesity, abdominal obesity and related risk factors in urban adults from 33 communities of Northeast China: the CHPSNE study. BMC Public Health. 2012;12(1) https://doi.org/10.1186/1471-2458-12-967.

64. Haynes A, Kemps E, Moffitt R. The moderating role of state inhibitory control in the effect of evaluative conditioning on temptation and unhealthy snacking. Physiol Behav. 2015;152:135-42 https://doi.org/10.1016/ j.physbeh.2015.09.020.

65. Lokken KL, Boeka AG, Austin HM, Gunstad J, Harmon CM. Evidence of executive dysfunction in extremely obese adolescents: a pilot study. Surg Obes Relat Dis. 2009;5:547-52 https://doi.org/10.1016/j.soard.2009.05.008.

66. Meule A, Lutz AP, Vogele C, Kubler A. Impulsive reactions to food-cues predict subsequent food craving. Eat Behav. 2014;15:99-105 https://doi.org/ 10.1016/j.eatbeh.2013.10.023.

67. Braden A, Flatt SW, Boutelle KN, Strong D, Sherwood NE, Rock CL. Emotional eating is associated with weight loss success among adults enrolled in a weight loss program. J Behav Med. 2016;39(4):727-32 https://doi.org/10. 1007/s10865-016-9728-8.

68. Braden A, Rhee K, Peterson CB, Rydell SA, Zucker N, Boutelle K. Associations between child emotional eating and general parenting style, feeding practices, and parent psychopathology. Appetite. 2014;80:35-40.

69. Adriaanse MA, Prinsen S, Huberts d W, Jessie C, de Ridder DT, Evers C. 'I ate too much so I must have been sad': emotions as a confabulated reason for overeating. Appetite. 2016;103:318-23 https://doi.org/10.1016/j.appet.2016. 04.028.
70. Evers C, De Ridder DTD, Adriaanse MA. Assessing yourself as an emotional eater: Mission impossible? Appetite. 2011;57(2):536.

71. Evers C, de Ridder DTD, Adriaanse MA. Adequately predicting emotional eating with self-reports: Not as easy as pie. Health Psychol. 2010;29(4):344-5

72. Watts J. China's cosmetic surgery craze. Lancet. 2004;363:958 https://doi.org/ 10.1016/S0140-6736(04)15832-7.

73. Bašková M, Holubčíková J, Baška T. Body-image dissatisfaction and weightcontrol behaviour in slovak adolescents. Cent Eur J Public Health. 2017;25(3) 216-21 https://doi.org/10.21101/cejph.a4724.

74. Kostanski M, Gullone E. Adolescent body image dissatisfaction: relationships with self-esteem, anxiety, and depression controlling for body mass. J Child Psychol Psychiatry. 1998;39(2):255-62 https://doi.org/10.1111/1469-7610. 00319.

75. Fernandes J, Ferreira-Santos F, Miller K, Torres S. Emotional processing in obesity: a systematic review and exploratory meta-analysis. Obes Rev. 2018; 19(1):111-20 https://doi.org/10.1111/obr.12607.

76. Beydoun MA. The interplay of gender, mood, and stress hormones in the association between emotional eating and dietary behavior. J Nutr. 2014; 144(8):1139-41 https://doi.org/10.3945/jn.114.196717.

77. Walfish S, Brown TA. Self-assessed emotional factors contributing to increased weight in presurgical male bariatric patients. Bariatric Nurs Surg Patient Care. 2009:4(1):49-52 https://doi.org/10.1089/bar.2009.9991.

78. Tok S, Catikkas F, Canpolat AM, Koyuncu M. Body image satisfaction and dissatisfaction, social physique anxiety, self-esteem, and body fat ratio in female exercisers and nonexercisers. Soc Behav Pers An Int J. 2010;38(4): 561-70 https://doi.org/10.2224/sbp.2010.38.4.561.

79. Braden A, Emley E, Watford T, Anderson LN, Musher-Eizenman D. Selfreported emotional eating is not related to greater food intake: results from two laboratory studies. Psychol Health. 2019;28 https://doi.org/10.1080/ 08870446.2019 .1649406 .

\section{Publisher's Note}

Springer Nature remains neutral with regard to jurisdictional claims in published maps and institutional affiliations.
Ready to submit your research? Choose BMC and benefit from:

- fast, convenient online submission

- thorough peer review by experienced researchers in your field

- rapid publication on acceptance

- support for research data, including large and complex data types

- gold Open Access which fosters wider collaboration and increased citations

- maximum visibility for your research: over $100 \mathrm{M}$ website views per year

At BMC, research is always in progress.

Learn more biomedcentral.com/submissions 